\title{
Reduction of blood loss by restoration of platelet levels using fresh autologous blood after cardiopulmonary bypass
}

\author{
J. G. WA GSTAFFE, A. D. CLARKE, and P.W. JACKSON ${ }^{1}$ \\ Departments of Cardiac Surgery and Anaesthetics, The Royal Infirmary, Manchester
}

Two methods of taking off two units of blood before bypass, storing it at $4^{\circ} \mathrm{C}$, and giving it after heparin reversal at the end of bypass are described and compared.

When the blood was taken into acid citrate dextrose before the patient was heparinized, the platelet count increased by $22,000 / \mathrm{mm}^{3}$ and blood loss was reduced by $26 \cdot 7 \%$ (a significant decrease).

Blood, taken after heparin was given, gave a similar platelet increase after retransfusion but the resulting decrease in blood loss was $17.6 \%$ (a non-significant decrease). Neither difficulties nor complications were noted using the technique in 38 patients.

Thrombocytopenia after open heart surgery is common and may be associated with increased blood loss. During the use of pump oxygenators for cardiopulmonary bypass the whole of the patient's circulating blood volume is exposed to progressive mechanical trauma which produces changes in the factors affecting coagulation (Rothnie, Norman, Steele, and Kinmonth, 1960; Kendall and Lowenstein, 1962; Gans and Krivit, 1962; Gibbon and Camishion, 1964), in particular a reduction in circulating platelets.

Grindon and Schmidt (1969) perfused with platelet-poor blood wthout impairing coagulation, but, in our experience, the immediate post-perfusion thrombocytopenia has been the main cause of impaired coagulation. Low platelet counts of $70,000 / \mathrm{mm}^{3}$ (Couch, 1967) and $60,000 / \mathrm{mm}^{3}$ (Oberman, 1967) have been quoted, but, like Kahn, Strang, and Wilson (1968), we regard levels below $50,000 / \mathrm{mm}^{3}$ as critical.

Exposing the whole circulating blood volume to mechanical trauma appeared undesirable. Blood was therefore withdrawn from the patient before bypass (Dodrill et al., 1957; Hardesty, Bayer, and Bahnson, 1968). This autologous blood was later returned. Removal of blood from even the very ill patient was considered feasible as these patients had an increased blood volume due to congestive heart failure.

The purpose of this study was to evaluate the

1Correspondence to P.W.J., Dept. of Anaesthetics above technique by measuring the platelet levels and total blood loss after the perfusion.

Heparin reduces circulating platelets in vivo (Kirby, 1958) and in vitro (Perkins, Osborn, and Gerbode, 1958), but as acid citrate dextrose (ACD) is reported to increase platelet survival (Perkins et al., 1958), the effect of using either heparin or $\mathrm{ACD}$ as the anticoagulant was also investigated.

\section{METHOD}

Two groups of patients operated on by two different surgical teams were investigated and compared with their respective control groups. The operations performed in these groups are listed in Table I.

The operations performed in both control groups were consecutive cases starting before this study. In both study groups patients were also consecutive. Patients who had known preoperative coagulation disorders and any patient who bled due to faulty surgical haemostasis were excluded from both control and study groups.

GROUP 1 (23 patients) From each patient $840 \mathrm{ml}$ of blood was collected in two $540-\mathrm{ml}$ transfusion bottles, each containing $120 \mathrm{ml}$ of ACD anticoagulant. The blood was taken approximately 5 minutes before heparin was given for bypass, via a $100-\mathrm{cm}$ tube of $4 \mathrm{~mm}$ internal diameter (ID) inserted in the right atrium and secured by a purse-string suture (Fig. 1). In this group the rate of bleeding was controlled by the arterial and venous pressures, the systolic arterial pressure not being allowed to fall below $70 \mathrm{mmHg}$. Recovery from the brief period of hypotension occurred when half the blood volume withdrawn was replaced with $5 \%$ 


\section{T A B LE I}

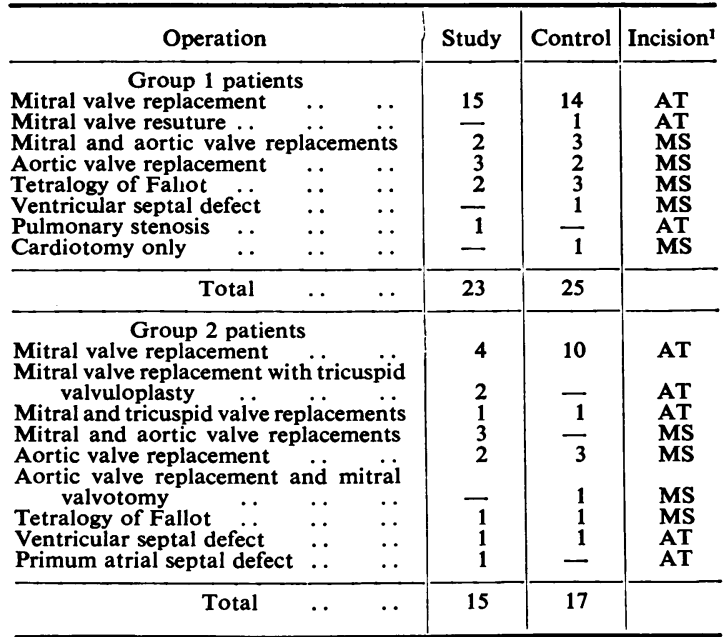

$\sqrt{\mathrm{AT}}=$ antero-lateral thoracotomy; $\mathrm{MS}=$ median sternotomy.

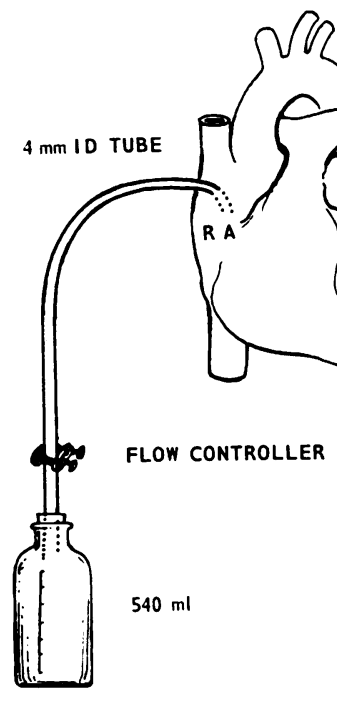

GROUP

FIG. 1. Method of collection of autologous ACD blood.

dextrose in $0.18 \%$ normal saline, which was given after the collection of blood so as to avoid dilution of the collected blood.

GROUP 2 (15 patients) Ten minutes after giving 3 $\mathrm{mg} / \mathrm{kg}$ body weight of heparin, $1,080 \mathrm{ml}$ of heparinized blood was collected into two $540-\mathrm{ml}$ bottles as bypass began. The priming fluid $(5 \%$ dextrose in $0.18 \%$ normal saline) in the venous tube of the extracorporeal circuit was first displaced by the patient's blood. This blood was then collected via a $12 \mathrm{~mm}$ ID polycarbonate straight connector with a Luer side arm, inserted in the venous tube near the entry port to the oxygenator. Attached to the Luer side arm was a $20 \mathrm{~cm}$ length of $4 \mathrm{~mm}$ ID tube for collection of blood (Fig. 2).

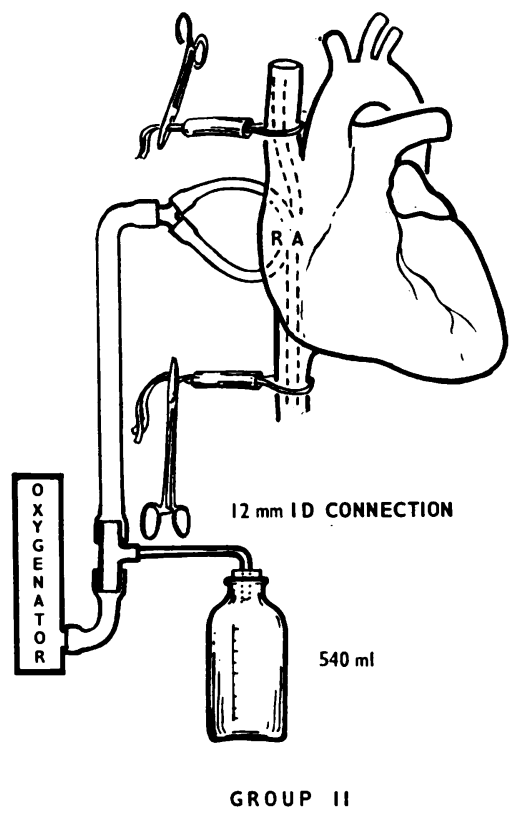

FIG. 2. Method of collection of autologous heparinized blood.

The collected blood from both groups of patients was stored at $4^{\circ} \mathrm{C}$ until required at the end of bypass. Patients in both study groups received no donor blood before bypass but, to compensate for the volume of blood withdrawn, a similar volume of ACD donor blood, sometimes up to five days old, was added to the pump oxygenator prime to maintain a safe operating volume within the Rygg oxygenator during bypass. The prime was buffered with sodium bicarbonate $(25 \mathrm{mEq} /$ litre $)$. The volume of the priming fluid $(5 \%$ dextrose in $0.18 \%$ normal saline) was calculated at $20 \mathrm{ml} / \mathrm{kg}$ body weight (Cooley, Beall, and Grondin, 1962). All the perfusions were normothermic except in those cases involving surgery of the aortic valve in which hypothermia $\left(32^{\circ}\right.$ C oesophageal) was used.

When the bypass was completed, intravenous protamine sulphate was given to neutralize circulating heparin, the dose required having been determined by a heparin protamine titration (Perkins et al., 1956).

The autologous blood was then returned to the patient via a drip set connected to the arterial line of the pump oxygenator. This drip set was attached to the luer side arm of $12 \mathrm{~mm}$ ID polycarbonate connexion proximal to the arterial pump. The introduction of blood at this point of the circuit allowed the stored blood to be warmed and filtered before it entered the 
patient. The remaining autologous blood in the arterial line was displaced with blood from the oxygenator.

The infusion time varied from 5 to 15 minutes, being controlled by the central venous pressure (CVP) which was maintained below $20 \mathrm{~cm} \mathrm{H}_{2} \mathrm{O}$. In group 1, calcium gluconate, $1.0 \mathrm{~g}$ per litre of blood, was given to cover the effect of citrate contained in the ACD autologous blood. In group 2, a further dose of protamine sulphate, $30 \mathrm{mg} /$ litre, was later given to neutralize the heparin in the autologous blood. After all the autologous blood had been returned to the patient stored donor blood was given to replace overall blood loss (the age of this blood varied from two to five days).

Serial platelet counts according to the method of Lempert (1935) were made at the following times: (1) before operation; (2) at the end of bypass ; (3) 10 minutes after autologous blood transfusion; (4) on return to the intensive care unit ; $(5)$ on the first postoperative day; and (6) on the second postoperative day.

All platelet counts were made as routine haematological procedures by an experienced technician who was unaware of the nature of the study.

Measurement of the total blood loss was measured in millilitres per square metre $\left(\mathrm{ml} / \mathrm{m}^{2}\right)$; this began immediately after giving the autologous blood and was maintained until all chest drains were removed, as described by Smith et al. (1964). Re-exploration of two patients was performed, one from each study group, due to haemothorax. These patients' blood loss figures are included in Table III.

The platelet counts and blood loss data for the study groups were compared with those for the respective control groups who received only donor ACD blood after bypass. These data were compared using Student's $t$ test, accepting $\mathrm{P}<0.05$ as a level of significance.

\section{RESULTS}

The mean platelet increases for both groups, due to autologous blood transfusion, are shown in Table II. In group 1, this improvement over the

T A B L E II

MEAN VALUES FOR PLATELET COUNTS BEFORE AND

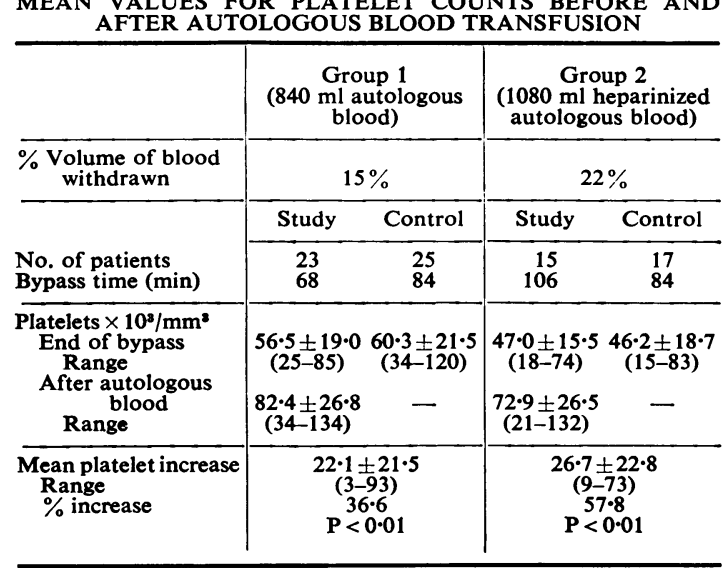

control group was shown by a mean increase of $22,100 \pm 21,500 / \mathrm{mm}^{3}$ after transfusion. This represents a $36 \cdot 6 \%$ increase when compared with the control group $(\mathrm{P}<0.01)$. The mean bypass time for the study group was 16 minutes less than for the control. Similarly, in group 2 the improvement over the control group was shown by a mean increase of $26,690 \pm 22,800 / \mathrm{mm}^{3}$ after transfusion. This represents a $57.8 \%$ rise compared with a control group $(P<0.01)$. In study group 1 , the smallest increase of platelets in any one patient was $3,000 / \mathrm{mm}^{3}$ and the highest increase was $93,000 / \mathrm{mm}^{3}$. Similarly, for study group 2 the lowest increase was $9,000 / \mathrm{mm}^{3}$ and the highest was $73,000 / \mathrm{mm}^{3}$ after autologous blood transfusion. The average blood volumes withdrawn were $15 \%$ for group 1 and $22 \%$ for group 2 . Figure 3 illustrates the typical changes in arterial and central venous blood pressures during the collection of blood in a patient from study group 1 . The brief period of hypotension was improved by the transfusion of $5 \%$ dextrose in $0.18 \%$ normal saline.

The immediate and later effects of autologous blood transfusion in both groups are shown in Figures 4 and 5 . The storage time for blood in group 1 averaged 15 minutes longer than in group 2 as this blood was withdrawn earlier. Fresh blood or platelet concentrates were not required for any patient in either study group.

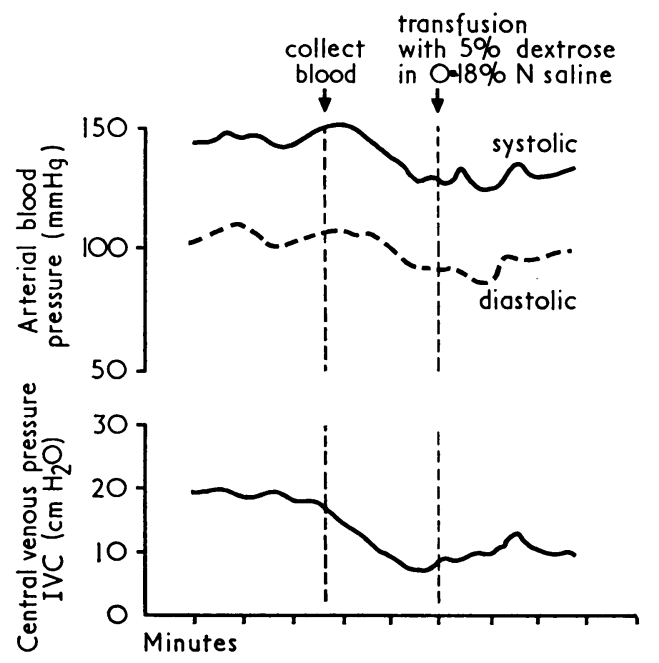

FIG. 3. Typical tracing of blood pressure and central venous pressure during bleeding in a patient in group 1.

BLOOD Loss The mean total blood loss figures $\left(\mathrm{ml} / \mathrm{m}^{2}\right)$ from the end of bypass are shown in 


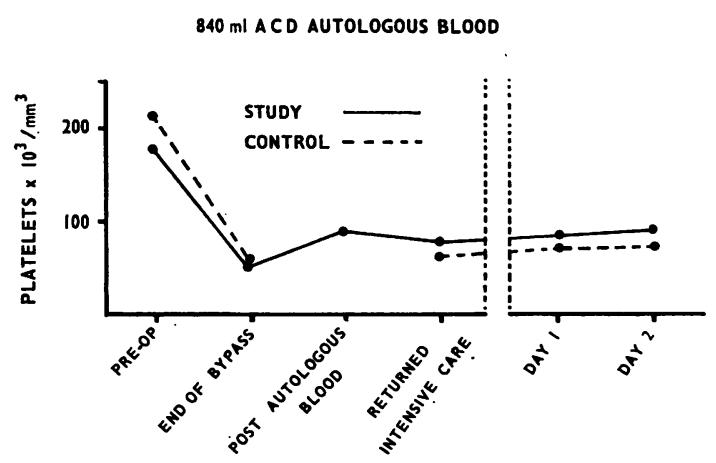

FIG. 4. Mean platelet counts in 48 patients in study group 1 and its control.

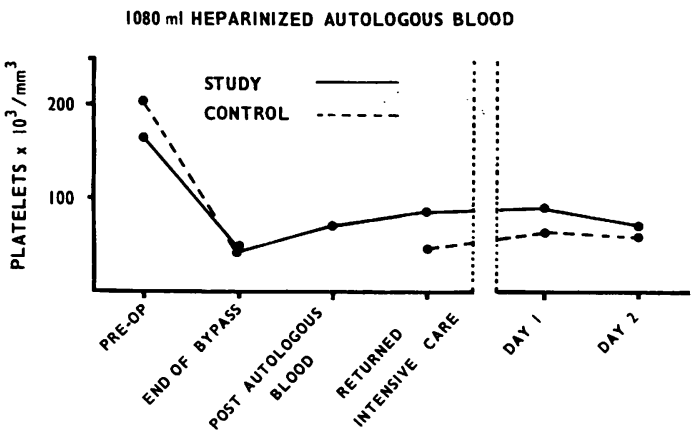

FIG. 5. Mean platelet counts in 32 patients in study group 2 and its control.

Table III. Blood loss in group 1 shows that the patient who received autologous ACD blood produced a significant reduction of $26.7 \% \quad(P<0.05$ one-tail Student's $t$ test) as compared with the control figures. Blood loss in group 2 shows that after transfusion with heparinized autologous blood a reduction of $17.6 \%$ was produced, which

T A B L E I I I

MEAN VALUES FOR BLOOD LOSS $\left(\mathrm{ml} / \mathrm{m}^{2}\right)$ AFTER AUTOLOGOUS BLOOD TRANSFUSION

\begin{tabular}{|c|c|c|c|c|}
\hline & \multicolumn{2}{|c|}{ Group 1} & \multicolumn{2}{|c|}{ Group 2} \\
\hline & Study & Control & Study & Control \\
\hline $\begin{array}{l}\text { No. of patients } \\
\text { Surface area } \\
\quad\left(\mathrm{m}^{2}\right) \\
\text { Total blood loss } \\
\left(\mathrm{ml}^{2} \mathrm{~m}^{2}\right) \\
\text { Range }\end{array}$ & $\begin{array}{c}231 \\
1 \cdot 61 \\
1748 \pm 1163 \\
343-4394\end{array}$ & $\begin{array}{c}25 \\
1 \cdot 64 \\
2388 \pm 1059 \\
1408-6749\end{array}$ & $\begin{array}{c}15^{1} \\
1 \cdot 54 \\
1379 \pm 446 \\
797-2556\end{array}$ & $\begin{array}{c}17 \\
1 \cdot 54 \\
1673 \pm 896 \\
646-3274\end{array}$ \\
\hline $\begin{array}{l}\text { Mean reduction } \\
\% \text { Decrease }\end{array}$ & \multicolumn{2}{|c|}{$26.7 \stackrel{639}{P}<0.05$} & \multicolumn{2}{|c|}{$\begin{array}{c}17 \cdot 6 \stackrel{294}{P}>0.1 \\
(1 \text { tail test })\end{array}$} \\
\hline
\end{tabular}

1 One patient from each group was re-explored due to haemothorax. was not significant $(P>0 \cdot 1$, one-tail Student's $t$ test) as compared with figures for blood loss in control patients in group 2 .

\section{DISCUSSION}

This investigation was begun because we were concerned about the high blood loss often associated with platelet counts below $50,000 / \mathrm{mm}^{3}$.

The accepted treatment of postoperative haemorrhage associated with a low platelet count is by the transfusion of fresh blood (Oberman, 1967) or platelet concentrates (Woods, Taswell, Kirklin, and Owen, 1967). As a method of reducing these demands on the transfusion service, autologous blood was used in a similar manner to that described by Hardesty et al. (1968). In group 2 of our series, our results confirm their work using heparin as the anticoagulant. Our methods differed in that smaller volumes were collected and stored in glass bottles at $4^{\circ} \mathrm{C}$ to increase platelet survival (Goldstein, Bunker, and McGovern, 1964). In group 1 of our series, when ACD autologous blood was used, the improvement in blood loss became significant $(P<0.05)$.

We feel it is important not to return the autologous blood until after the protamine sulphate has neutralized the circulating heparin and is seen to be effective by the production of visible clots. This reduces the loss of the transfused autologous blood from the sites of haemorrhage. During the transfusion the CVP was increased but was not allowed to rise above $20 \mathrm{~cm} \mathrm{H}_{2} \mathrm{O}$ to prevent circulatory overload.

In our study these methods for raising the platelet count did not produce as high an increase as that produced by the transfusion of platelet concentrates, described by Woods et al. (1967), who extracted donor platelets from up to 8 units of blood collected on the morning of the operation. We feel that our method is as effective in reducing blood loss and has the virtue of simplicity and of supplying autologous platelets, and possibly other coagulation factors.

Figures 4 and 5 illustrate that the immediate increases in the mean platelet count in both study groups were maintained at a higher level than in the control groups up to the second postoperative day. It is interesting to note that in group 1 the mean platelet count 10 minutes after the autologous blood had been given was higher than after surgery was completed. After bypass and heparin reversal the utilization of platelets should be at its peak, and this may suggest that platelets stored in ACD blood are immediately more effective than those stored in heparin. 
The mean bypass time in study group 1 was reduced by 16 minutes and this was achieved without making any changes in surgical technique between the control and study groups. In this group the majority of operations were for mitral valve replacement and the reduced bypass time can probably be explained by increased experience. However, in study group 2, the reason for increased bypass time is that some operations for replacement of the mitral valve are accompanied by either aortic or tricuspid valve surgery.

The greater part of the decrease in platelets occurs within 15 minutes after bypass begins. Further but small reductions continue to occur until the platelet count becomes stabilized about 30 minutes after the start of bypass (Kendall and Lowenstein, 1962). Therefore we did not anticipate any improvement in the platelet count in study group 1 due to reducing the mean bypass time to 68 minutes as compared with the control group mean bypass time of 84 minutes.

On the other hand, prolonged bypass time is likely to affect other clotting factors and so may increase postoperative blood loss. The longer bypass times in study group 2 as compared with the control (Table II) could have biased the results and may explain the smaller reduction in blood loss after heparinized autologous blood in group 2 as compared with group 1 (Table III).

In our study the use of autologous blood by these simple techniques has raised platelet counts from critical to acceptable post-bypass levels. At times it may not be possible to collect blood into ACD as in group 1, due, for example, to a low circulating blood volume or poor cardiac output. In these circumstances it may be preferable to use the method described for group 2 .

We are indebted to Mr. H. F. M. Bassett and Mr. K. Bloor for their co-operation in allowing us to study their patients.

We are grateful for the diagrams produced by the Department of Medical Illustration, Manchester Royal Infirmary.

We should like to extend our gratitude to Dr. J. E. MacIver for advice and assistance, to Miss J. Bottomley for technical assistance, to Mr. E. Moss for valuable assistance with the assessment of data, and to Mrs. I. Alcock for secretarial assistance.

\section{REFERENCES}

Cooley, D. A., Beall, A. C., and Grondin, P. (1962). Openheart operations with disposable oxygenators, 5 per cent dextrose prime, and normothermia. Surgery, 52, 713.

Couch, N. P. (1967). The role of the blood bank in cardiac surgery. In Cardiac Surgery, p. 54, edited by J. C. Norman. Meredith Publishing Company, New York, and Butterworth, London.

Dodrill, F. D., Marshall, N., Nyboer, J., Hughes, C. H., Derbyshire, A. J., and Stearns, A. B. (1957). The use of the heart-lung apparatus in human cardiac surgery. $J$. thorac. Surg., 33, 60.

Gans, H., and Krivit, W. (1962). Problems in hemostasis during open heart surgery. IV. On the changes in the blood clotting mechanism during cardiopulmonary bypass procedures. Ann. Surg., 155, 353.

Gibbon, J. H., and Camishion, R. C. (1964). Problems in hemostasis with extracorporeal apparatus. Ann. N.Y. Acad. Sci., 115 (Art 1), 195.

Goldstein, R., Bunker, J. P., and McGovern, J. J. (1964). The effect of storage of whole blood and anticoagulants upon certain coagulation factors. Ann. N.Y. Acad. Sci., 115 (Art 1), 422.

Grindon, A. J., and Schmidt, P. J. (1969). Platelet-poor blood in open-heart surgery. New Engl.J. Med., 280, 1337.

Hardesty, R. L., Bayer, W. L., and Bahnson, H. T. (1968). A technique for the use of autologous fresh blood during open-heart surgery. J. thorac. cardiovasc. Surg., 56, 683.

Kahn, D. R., Strang, R. H., and Wilson, W. S. (1968). Clinical Aspects of Operable Heart Disease, p. 57. Appleton-Century-Crofts, New York (Division of Meredith Corporation).

Kendall, A. G., and Lowenstein, L. (1962). Alterations in blood coagulation and hemostasis during extracorporeal circulation; part 1. Canad. med. Ass. J., 87, 786.

Kirby, C. K. (1958). Discussion on blood changes. In Extracorporeal Circulation, edited by J. G. Allen, p. 264 Thomas, Springfield, Illinois.

Lempert, H. (1935). A modified technique for the enumeration of blood platelets. Lancet, 1, 151.

Oberman, H. A. (1967). The indications for transfusion of freshly drawn blood. J. Amer. med. Ass., 199, 93.

Perkins, H. A., Osborn, J. J., and Gerbode, F. (1958). The effect of heparin on the platelet count in vitro, with particular reference to the collection of blood for extracorporeal circulation. Amer. J. clin. Path., 30, 397.

, - - Hurt, R., and Gerbode, E. F. (1956). Neutralization of heparin in vivo with protamine. A simple method of estimating the required dose. J. Lab. clin. Med., 48, 223.

Rothnie, N. G., Norman, A. G., Steele, M., and Kinmonth, J. B. (1960). Changes in blood-coagulation due to perfusion for cardiac surgery. Brit. J. Surg., 48, 272.

Smith, B., Omeri, M. A., Melrose, D. G., Bentall, H. H., and Allwork, S. (1964). Blood-loss after cardiopulmonary bypass. Lancet, $2,273$.

Woods, J. E., Taswell, H. F., Kirklin, J. W., and Owen, C. A. (1967). The transfusion of platelet concentrates in patients undergoing heart surgery. Mayo Clin. Proc., 42, 318. 